\title{
$R$ v. Human Fertilisation and Embryology Authority, ex parte Blood Legal commentary
}

\author{
Mary Neal
}

\section{Introduction}

During the late 1990s and early 2000s, an unprecedented story unfolded in the UK media involving a young widow, Diane Blood, and her legal battle to bear the children of her late husband, Stephen, following his tragic death from meningitis at the age of only thirty. As the story unfolded in the media, the ethical and legal issues were explored in the courts and in academic commentaries. ${ }^{1}$ For all the controversy the case generated, the applicable law was clear and straightforward: the governing statute at the time of the case, the Human Fertilisation and Embryology Act 1990 (hereafter 'the Act'), prohibited the storage or use of gametes without the clear written consent of the gamete provider. ${ }^{2}$ Since the Act was unambiguous, and since Stephen Blood had never given his written consent to the storage or use of his sperm, there was no possibility of the HFEA permitting treatment within the UK. The question, therefore, was whether the HFEA would authorise the removal of the sperm abroad for treatment in another EU country. Initially, they refused, so the issue became a procedural one: had the HFEA reached their decision after appropriate consideration of the various factors which they were obliged to take into account?

My concern here is not to examine the points of law which were directly at stake in the case, but to identify some wider themes which have relevance beyond the case itself and examine them from a predominantly (though not exclusively) legal perspective.

\footnotetext{
${ }^{1}$ See further DM Morgan and RG Lee, 'In the Name of the Father? Ex parte Blood: Dealing with Novelty and Anomaly' (1990) The Modern Law Review 60(6): 840-856

${ }^{2}$ Human Fertilisation and Embryology Act 1990, Schedule 3.
} 


\section{The absence of consent and the principle of autonomy}

As Laurie J notes, Stephen Blood was unconscious throughout both of the procedures to retrieve sperm samples from him. Where a patient is unconscious, and so clearly lacking in autonomy, there is (obviously) no requirement to obtain his consent for an intervention. In discussing a patient who was unconscious throughout his hospitalisation, therefore, the principle of patient autonomy and the absence of consent to these interventions are irrelevant. Because this case involves assisted reproduction and the Act, however, it is relevant to have regard to the fact that Stephen Blood never consented under that statute; he never sought nor consented to 'treatment together' with his wife under the Act. Putting herself in the applicant's position, Jackson J reflects that:

From the point of view of the applicant, who desperately wants to preserve the option of bearing her late husband's child, it seems cruel that a legal technicality could force the destruction of her husband's sperm. ${ }^{3}$

Here, Jackson $\mathbf{J}$ is trying to see the issue from Mrs Blood's perspective, rather than endorsing this way of looking at the legal requirement for consent. For far from being a 'legal technicality', or a needlessly cruel impediment to Mrs Blood's achievement of her (and reportedly her late husband's) dream of a family, the written consent of the parties seeking treatment is of the utmost importance under the Act and has been described as one of the "twin pillars' of the statutory regime. ${ }^{4}$ Jackson $\mathrm{J}$ emphasises that the requirement for consent under the Act must also be seen as part of a whole process of deciding to embark upon treatment when she observes that 'Stephen Blood did not give consent in writing and he did not have an opportunity to receive counselling or be provided with such relevant information as is proper. ${ }^{5}$

Autonomy has a shadowy presence in discussions regarding what deceased persons and persons with permanent incapacity 'would have wanted'. We cannot really respect the autonomy of such persons, of course, but in attempting to estimate what their wishes would have been, we are trying to do more than simply act in what we think are their 'best interests'

\footnotetext{
3 Jackson J, paragraph 9.

${ }^{4}$ S Sheldon, 'Evans v Amicus Healthcare; Hadley v Midland Fertility Services—Revealing Cracks in the Twin Pillars' (2004) Child and Family Law Quarterly 16:437

${ }^{5}$ Jackson J, paragraph 5, emphasis added.
} 
(if they are alive), or act in a way that is objectively 'respectful' (if they are dead). Insofar as we try to respect such persons personally, rather than impersonally, it could be argued that we are influenced by the 'imprint' of their autonomy, so that in such cases, autonomy is neither truly present nor truly absent as a factor. ${ }^{6}$ In the Blood case, although there was 'no hard evidence of a clear and settled wish in the event of death', ${ }^{7}$ the court had some evidence of what Mr Blood's wishes had been during his lifetime. As Laurie J remarks,

The applicant has argued that she and her husband were strongly committed to starting a family, and there is no reason to doubt this, nor should we dismiss lightly the common objective of the couple. ${ }^{8}$

There was, however, no evidence of Mr Blood ever having contemplated assisted reproduction. This is relevant because assisted reproductive techniques (ARTs) raise particular ethical issues; for example, some people abhor the destruction of human embryos, which is a routine consequence of assisted reproduction. It is impossible, therefore, on the basis of Mrs Blood's testimony that she and her husband wished to start a family without assistance, to draw the conclusion that he would have been agreeable to the use of ARTs in pursuit of the same end. Not all of those who would countenance the former would also countenance the latter.

This difference alone ought to dissuade any court from believing it can determine how $\mathrm{Mr}$ Blood would have regarded his wife's plans. In fact, Mrs Blood's intentions were distinguished from what they envisaged together during his lifetime not only by the use of ARTs, but also because she proposed to conceive and bear a child after his death. Stephen Blood may well have contemplated the enterprise of conceiving and raising a child together with his wife; but the prospect of his wife conceiving and raising a child alone, after his death-a child with whom he could never have any kind of personal relationship, and could never 'parent' - is so far removed from what would have been within his contemplation while alive that the latter can hardly be relevant. ${ }^{9}$ Indeed, we might choose to interpret his wife's account of their joint plans as evidence that Stephen Blood seems to have wanted to be a parent, not to father a genetic child whatever the circumstances.

\footnotetext{
${ }^{6}$ Jackson J acknowledges (but does not endorse) this kind of argument at paragraph 16 of her judgment.

${ }^{7}$ Laurie J, paragraph 12.

${ }^{8}$ Laurie J, paragraph 11.

${ }^{9}$ Laurie J acknowledges this at paragraph 11 of his judgment.
} 
If we decide that it may well have been parenthood that Stephen Blood was enthusiastic about (and the language of 'starting a family' is suggestive of this), then nothing his wife did after his death could have achieved that for him. Only if his wish to start a family was motivated mainly by a burning desire to secure his genetic legacy could we reasonably regard his wife's posthumous plans as being in fulfilment of 'what he would have wanted'; and even if we knew this to be so, there seems no reason why the law should facilitate such an endeavour (indeed there may be strong policy reasons for not doing so). In any case, Diane Blood seems to have made no such claim.

Since Mr Blood was unconscious when the sperm was extracted, and was deceased by the time of the litigation, the issues of his consent and autonomy arose only indirectly in the case, via the acknowledgment that he never consented to treatment under the Act and the evidence about his wishes while alive. Mrs Blood's autonomy might also be relevant, however. Jackson J considers this:

Mrs Blood might invoke her reproductive autonomy. She wishes to become a mother and she has a compelling interest in making this critically important decision about her body and her future family life for herself. ${ }^{10}$

In the view of Jackson J, Mrs Blood's personal autonomy was simply one ethical principle which had be balanced against others, notably the need for a clear and consistent application of the framework set out in the Act. ${ }^{11}$ Although 'patient autonomy' often appears to trump other values in healthcare law cases involving competent patients seeking to exercise decisional autonomy in relation to medical treatment, that is not the context here; patient autonomy has been held not to support any right of patients to insist on receiving particular treatments. ${ }^{12}$ As such, we are dealing in this case with autonomy as an abstract ethical principle, albeit an important one. The only sense in which autonomy seems to be relevant in a legal sense in this case is the sense in which it probably forms part of the ideological scaffolding of the right to free movement which ultimately won the day for Mrs Blood.

\footnotetext{
10 Jackson J, paragraph 16.

11 Jackson J, paragraph 19.

${ }^{12} R$ (on the application of Burke) v. General Medical Council [2005] EWCA Civ 1003
} 


\section{'Treatment' and patients}

Although questions regarding what constitutes 'treatment' and who constitutes a 'patient', legally-speaking, were not directly at issue in this case, the case prompts some reflection on these matters. Considering Mr Blood first, he was clearly a patient while unconscious in hospital, until the point at which he was declared dead. When dealing with an unconscious patient, healthcare professionals have a legal and ethical obligation to act in the patient's 'best interests' (to ensure beneficence and patient-centred treatment). With this in mind, Laurie $\mathrm{J}$ has strong words for the professionals who acquiesced with Mrs Blood's request that sperm samples be extracted:

the unauthorised invasion of [Mr Blood's] bodily integrity is unequivocally an assault, unless it can be demonstrated that it was in his best interests, as a patient, to undergo the particular procedure...there is no direct benefit to Mr Blood whatsoever; neither immediately because he is in a coma, nor longer term since the interventions clearly occurred in anticipation of his death to bring about a benefit that would only arise once death had occurred. ${ }^{13}$

The interventions to extract sperm from an unconscious, dying man had no possibility of therapeutic value for him and were not motivated by clinical need. As Laurie J notes, not only do they fail the 'best interests' test; they 'unequivocally' amounted to assault. As such, they cannot plausibly be regarded as 'treatment'.

What of Mrs Blood? The whole case seems to be framed as if she were a patient (someone seeking to exercise her right to 'seek treatment abroad'). Mrs Blood was not a patient at the time of this case, however; she had no diagnosis, and was not under the care of a doctor as far as we know. Instead, it is more accurate to say that she sought to become a patient. Did she become a patient when she was finally granted leave to take the sperm abroad and use it to create her family? I think this is questionable.

In paragraph 7 of his judgment, Laurie J quotes from section 2(1) of the Act, which defines 'treatment services' as 'medical, surgical or obstetric services provided to the public or a

\footnotetext{
${ }^{13}$ Laurie J, paragraph 11.
} 
section of the public for the purpose of assisting women to carry children.' When such a statutory definition exists, it supersedes (for the context covered by the Act) any common law understandings that may apply in other contexts. According to this definition, the intervention Mrs Blood seeks to avail herself of is 'treatment'. In my view, however, the statutory definition (which is undoubtedly authoritative in this case) is undesirably wide.

I have argued recently elsewhere ${ }^{14}$ that to count as 'treatment' in the healthcare context, an intervention should either have intended therapeutic value for the person intervened-upon (as most cases of treatment do), or have a strong public interest justification (such as the removal of a healthy kidney from a living donor, which has no therapeutic value to the donor). ${ }^{15}$ In fact, in most cases of treatment, both of these elements are present. ${ }^{16}$ So which of these elements is present in Mrs Blood's 'treatment'? It is difficult to regard it as therapeutic, since Mrs Blood (as far as we know) had no relevant illness, nor any physical impediment to conceiving. Neither is her project straightforwardly justified by 'public good' considerations; indeed, it could be argued that there are public good considerations (perhaps associated with child welfare and the proper treatment of unconscious patients) which weigh against allowing it.

I am conscious of the fact that other 'treatments' currently so regarded may also fall foul of the test I have proposed above. For example, and staying in the same area, my test could lead to questions about whether assisted reproduction techniques were 'treatment' in the context of single people or same-sex couples (who may seek to access them despite being neither ill nor infertile). A short answer to this is that I believe that a public interest justification can be made in these cases (along the lines that denying ARTs to single and gay people risks driving people who are desperate to have children into risky unregulated inseminations or even unwanted intimate physical relationships which may be traumatic for them); moreover, Mrs Blood's case can be distinguished on the basis that what she sought was to bear the child of a particular man, now deceased. This is a preference (albeit a very strong and persistent one), not a condition; thus, the steps taken in pursuit of it ought to be understood as an exercise in preferencesatisfaction, not as treatment. The line between the two is not always clear, but sometimes, as in this case, it is.

\footnotetext{
14 'Locating lawful abortion on the spectrum of "proper medical treatment"' in S Fovargue and A Mullock (eds.) The Legitimacy of Medical Treatment: What Role for the Medical Exception? (Routledge, 2015) 124-141 ${ }^{15}$ It must also, of course, be justified by patient consent, or where that is impossible, by necessity or a 'best interests' calculus.

${ }^{16}$ Neal $n 14$ above, passim
} 


\section{Human dignity}

Like the principle of respect for autonomy, the value of human dignity is both an ethical and a legal value. ${ }^{17}$ Despite the derision of some famous detractors, ${ }^{18}$ the idea of dignity has enjoyed a renaissance in recent years, not least in the context of bioethics, where a growing body of literature is attempting to redress the neglect of the idea in that context (a neglect which may stem, at least partly, from the invisibility of dignity within the ethical approach—principlism—which dominated the first several decades of bioethical scholarship). ${ }^{19}$ Considering the Blood case from a dignity perspective may prompt dignityrelated anxieties about the treatment of Stephen Blood while unconscious. As Laurie J puts it, Mr Blood was subjected to 'an intimate and highly invasive procedure' ${ }^{20}$ which offered 'no direct benefit to [him] whatsoever'. ${ }^{21}$ While his wife was presumably affected by shock and grief, the doctors were under an obligation to act professionally and in their patient's best interests. In requesting the sperm samples, Mrs Blood was regarding her husband as a potential father, which seems to have been consistent with the way she had always regarded him, and is not necessarily incompatible with respect for his equal human dignity. By retrieving the samples, however, the healthcare professionals treated Mr Blood not as a patient with equal human dignity and interests of his own (which would only be extinguished upon his death), but as a source of gametes. Presumably, amid the emotion of the situation, they were moved by Mrs Blood's appeals; in acting on them, however, they failed to respect the dignity of their patient, and their actions cannot be understood (as hers can) in terms of grief and shock.

\footnotetext{
${ }^{17}$ For an explanation of the importance of human dignity, and why it is not properly described as a 'principle' see M Neal (2014) 'Respect for human dignity as "substantive basic norm"' International Journal of Law in Context 10(1):26-46.

${ }^{18}$ See eg S Pinker (2008) 'The Stupidity of Dignity', The New Republic, available at: <http://www.tnr.com/ article/the-stupidity-dignity>; R Macklin (2003) 'Dignity is a Useless Concept', British Medical Journal 327: 1419-20; and M Bagaric, and J Allen (2006) 'The vacuous concept of dignity' Journal of Human Rights 5: 257270.

${ }^{19}$ See further D Beyleveld and R Brownsword, Human dignity in bioethics and biolaw (Oxford: OUP, 2001); C Foster, Human Dignity in Bioethics and Law (Oxford: Hart Publishing, 2011); and R Andorno (2013), 'The Dual Role of Human Dignity in Bioethics', Medicine, Health Care and Philosophy 16(4):967-73. The dominant 'principlist' approach prioritises 'four principles' identified by TL Beauchamp and JF Childress, Principles of Biomedical Ethics (4 ${ }^{\text {th }}$ edition, Oxford University Press, 1994).

${ }^{20}$ Laurie J, paragraph 8

${ }^{21}$ Laurie J, paragraph 11.
} 


\section{Conclusion}

The eventual outcome of the Blood litigation was, of course, a happy one for Mrs Blood, who was permitted to travel abroad for treatment and eventually gave birth to two of her late husband's genetic children. As serious as the legal issues considered above are, there is a sense in which the birth of two much-wanted children - and the creation of a happy family out of a tragic loss-represents a powerful counterargument to the concerns I have raised. As a number of cases concerning so-called 'wrongful conception' have emphasised, however, the acknowledgment that legal wrongs have taken place along the route to a child's coming into existence (and have even caused it) certainly does not lessen the extent to which that child is a 'blessing' in the eyes of the law. ${ }^{22}$ I think it is worth emphasising that principle in this context too. Whatever legal and ethical anxieties surrounded their conception, the Blood children are as valued by the law, by society, and of course by their remarkable mother, as any children ever were.

\footnotetext{
${ }^{22}$ See, eg, McFarlane and another v Tayside Health Board [2000] 2 AC 59, and Cattanach v Melchior (2003) 199 ALR 131.
} 